\title{
Evolution of the Global Inequality in Greenhouse Gases Emissions using Multidimensional Generalized Entropy Measures
}

\author{
Lorena Remuzgo, Carmen Trueba and José María Sarabia* \\ Department of Economics, University of Cantabria
}

\begin{abstract}
Given the cumulative consequences of climate change, global concentration of greenhouse gases (GHGs) must be reduced; being inequality in per-capita emissions levels a problem to achieve a commitment by all countries. Thus, the evolution of carbon dioxide $\left(\mathrm{CO}_{2}\right)$ emissions inequality has received special attention because $\mathrm{CO}_{2}$ is the most abundant GHG in the atmosphere. However, it is necessary to consider other gases to provide a real illustration of our starting point to achieve a multilateral agreement. In this paper, we study the evolution of global inequality in GHGs emissions during the period 1990-2011, considering the four main gases: $\mathrm{CO}_{2}$, methane $\left(\mathrm{CH}_{4}\right)$, nitrous oxide $\left(\mathrm{N}_{2} \mathrm{O}\right)$ and fluorinated gases (F-gases). The data used in this analysis is taken from the World Resources Institute [1] and the groups of countries are constructed according to the quantity of emissions that each country released into the atmosphere in the first year of study. For this purpose we use the multidimensional generalized entropy measures proposed by Maasoumi [2] that can be decomposable into the between- and within-group inequality components. The biggest fall in inequality is observed when we attach more weight to the emissions transfers between the most polluting countries and assume a low substitution degree among pollutants. Finally, some economic policy implications are commented.
\end{abstract}

Keywords: Multidimensional inequality, Generalized entropy indices, Econophysics, Environmental-economic interactions, Greenhouse gas emissions distribution.

JEL classification: Q50, C10.

${ }^{*}$ Corresponding author. Tel.:+34 942201635. Address: Av. Los Castros s/n 39005 Santander, Spain. E-mail address: jose.sarabia@unican.es 


\section{Introduction}

The increasing interest of physicists in complex economic and social systems has led to the emergence of the econophysics which is a new research field that applies the methods of statistical physics to problems in economics [3]. These applications have provided important insights into income inequality ${ }^{1}$, wealth inequality and consumption inequality. In this sense, it should be highlighted the econophysical models applied to income and wealth distributions in the works of Chakrabarti et al. [7], Ghosh et al. [8] and Inoue et al. [9].

Climate change is undoubtedly the main environmental problem faced by humanity nowadays. The combustion of fossil fuels has released greenhouse gases (GHGs) emissions which had led to climate change threatening, at the same time, human health and settlement, ecological system, agriculture and water resources [10]. Thus, the aim of the celebration of the United Nations Framework Convention on Climate Change (UNFCCC) in 1992 was to limit global GHGs ${ }^{2}$ emissions and stabilize their concentration in the atmosphere [12].

As carbon dioxide $\left(\mathrm{CO}_{2}\right)$ is the most abundant GHG in the atmosphere, the study of inequality in $\mathrm{CO}_{2}$ emissions has received special attention by many authors. Among all the papers dedicated to analyze the evolution of the international inequality in $\mathrm{CO}_{2}$ emissions, it is noted those carried out by Heil and Wodon [13, 14], Hedenus and Azar [15], Sun [16], Alcántara and Duro [17], Padilla and Serrano [18], Ezcurra [19], Groot [20], Cantore and Padilla [21], Mahony [22], Remuzgo and Sarabia [23] and Lawrence et al. [24], among others.

However, human activity carried out during the industrial era has led to a dramatic increase of both $\mathrm{CO}_{2}$ emissions and non- $\mathrm{CO}_{2}$ GHGs emissions. In this sense, the non- $\mathrm{CO}_{2}$ GHGs play an important role in understanding and curbing global climate change. The last Greenhouse Gas Bulletin [25] shows that the concentration of $\mathrm{CO}_{2}$, methane $\left(\mathrm{CH}_{4}\right)$ and nitrous oxide $\left(\mathrm{N}_{2} \mathrm{O}\right)$ has increased by 141, 260 and 120 percent since the year 1750, respectively. The increase in global $\mathrm{CO}_{2}$ concentration is largely due to the use of fossil fuels, while the observed increment in the concentration of $\mathrm{CH}_{4}$ and $\mathrm{N}_{2} \mathrm{O}$ has its origin mainly in the agricultural practices [26]. Unlike the previous GHGs, fluorinated gases (F-gases) do not have natural sources and only come from human activities. The three main categories of F-gases are:

\footnotetext{
${ }^{1}$ Several papers have studied distributional aspects of income in the main world economies [4-6].

${ }^{2}$ Annex A of the Kyoto Protocol [11] stated that the six main GHGs are: carbon dioxide $\left(\mathrm{CO}_{2}\right)$, methane $\left(\mathrm{CH}_{4}\right)$, nitrous oxide ( $\mathrm{N}_{2} \mathrm{O}$ ), hydrofluorocarbons (HFCs), perfluorocarbons (PFCs) and sulfur hexafluoride ( $\left.\mathrm{SF}_{6}\right)$.
} 
hydrofluorocarbons (HFCs), perfluorocarbons (PFCs) and sulfur hexafluoride ( $\mathrm{SF}_{6}$ ). Despite the fact that the concentration of these gases is still low, they are the most potent and longest lasting type of greenhouse gases emitted by human activities [27].

Additionally, mitigating non- $\mathrm{CO}_{2}$ GHGs can play an important role in global and regional climate strategy for two reasons. On the one hand, non- $\mathrm{CO}_{2}$ GHGs contribute more to global warming per unit mass than $\mathrm{CO}_{2}$ [28]. Thus, about 30 percent of anthropogenic greenhouse caused since preindustrial times can be attributed to them [29]. On the other hand, reduce non- $\mathrm{CO}_{2}$ GHGs emissions is a relatively cheap complement to the cost associated to $\mathrm{CO}_{2}$ only mitigation [30]. Therefore, the only consideration of $\mathrm{CO}_{2}$ emissions cannot reflect the real situation of the current problem of climate change, being necessary to incorporate such gases in climate economic analyses.

The use of multidimensional measures allows us to study inequality in emissions of the four main GHGs emissions: $\mathrm{CO}_{2}, \mathrm{CH}_{4}, \mathrm{~N}_{2} \mathrm{O}$ and F-gases, also known as long-term gases. Methane damages the atmosphere about 28 times more than $\mathrm{CO}_{2}$ over a 100 -year period ${ }^{3}$. The importance of this gas is due to its lifetime in the atmosphere -approximately 12 years ${ }^{4}$ which converts it into a key gas for curbing global warming because atmospheric concentrations of $\mathrm{CH}_{4}$ could respond to mitigation actions in the short term. Nitrous oxide is about 265 times more potent than $\mathrm{CO}_{2}$ at warming the atmosphere over a period of 100 years, having a long atmospheric lifetime -about 121 years-. F-gases are powerful GHGs with a global warming effect up to 23500 times greater than $\mathrm{CO}_{2}$. While HFCs are relatively shortlived, PFCs and $\mathrm{SF}_{6}$ can remain in the atmosphere for thousands of years [32].

With the celebration of the $17^{\text {th }}$ Conference of the Parties to the UNFCCC, the negotiations to adopt a multilateral agreement on climate change advanced. As the evidence of a decreasing path in GHGs emissions inequality could facilitate an international accord to reduce global GHGs concentration ${ }^{5}$ and brings the world closer to the state of maximal entropy, in this paper such inequality is analyzed from a multidimensional perspective. In particular, $\mathrm{CO}_{2}$, $\mathrm{CH}_{4}, \mathrm{~N}_{2} \mathrm{O}$ and F-gases emissions are studied in the period 1990-2011, using the generalized entropy measures proposed by Maasoumi [2]. In addition, these measures allow analyzing the contribution of the between- and within-group inequality components. Given that countries

\footnotetext{
${ }^{3}$ That is, the emission of 1 million ton of $\mathrm{CH}_{4}$ is equivalent to emit 28 million tons of $\mathrm{CO}_{2}$.

${ }^{4} \mathrm{CO}_{2}$ lifetime is not defined because it is not destroyed over time. Some of this gas is absorbed quickly but some will remain in the atmosphere for thousands of years [31].

${ }^{5}$ In addition, a decreasing trend of inequality in natural resources may lead to more social trust [33].
} 
have different population sizes, it is pertinent to characterize each one by their per-capita emissions, which in thermodynamic terminology are intensive variables. To the best of our knowledge, this is the first attempt to use inequality measures for analyzing, in a joint manner, the global distribution of GHGs emissions. In this sense, we are convinced that the use of quantitative methods for analyzing the historical trend of global inequality in GHGs emissions is a significant step toward solving climate change problem.

The specification of the multidimensional inequality indices applied in this paper [2] is an extension of the one-dimensional generalized entropy indices [34-37] which are based on the concept of entropy of the information theory [38, 39]. The generalized entropy indices consider the redundancy or non-randomness -measured as the difference of entropy with respect to the situation of maximum entropy-. This concept is also closely related to the Shannon [40] entropy, which comes from the statistical concept of entropy expressed by Boltzmann [41] and Gibbs [42]. In these works, the entropy is defined as a measure of the probability of all possible states of an isolated system; being, in the first case, the symbols of an information source and, in the second one, in a classical example, the position and velocity of the particles in an ideal gas. This parallelism is also reflected in its mathematical formulation which makes the thermodynamic definition of entropy equivalent to the notion of entropy in information theory, when the last one is multiplied by the Boltzmann constant [43] using the natural logarithm.

The structure of this paper is the following. In the second section, the Global Warming Potential, the main measure for comparing atmospheric emissions from various GHGs, is described. Next, the methodology used in the multidimensional inequality analysis is detailed. In the fourth section, the main results of the analysis are exposed. In section 5, a sensitivity analysis is carried out. Finally, with the conclusions of the paper, some economic policy implications are discussed.

\section{Global Warming Potential as a tool for comparing GHGs emissions}

Human activity releases into the atmosphere many gases that cause climate change. These gases have very different characteristics in terms of the amount emitted, the impact they have on the climate or their atmospheric lifetime. The design of climate policies which consider the joint action of various GHGs requires measures to establish equivalences among different emissions [44]. 
Among the measures proposed in the literature on climate change dedicated to this purpose, it is noted the Global Warming Potential (GWP). The concept of GWP was introduced in 1990 [45-48] in order to compare emissions of different GHGs over a given time horizon ${ }^{6}$. The GWP index is based on the radiative properties of GHGs sufficiently mixed. It measures the radiative forcing ${ }^{7}$ of a pulse emission of $1 \mathrm{~kg}$ of a gas $i$ relative to that of $1 \mathrm{~kg}$ of the reference gas, $\mathrm{CO}_{2}$.

The GWP of gas $j$ is defined by:

$$
G W P_{j} \equiv \frac{\int_{0}^{T H} R F_{j}(t) d t}{\int_{0}^{T H} R F_{r}(t) d t}=\frac{\int_{0}^{T H} a_{j} \cdot\left[C_{j}(t)\right] d t}{\int_{0}^{T H} a_{r} \cdot\left[C_{r}(t)\right] d t},
$$

where $G W P_{j}$ is the Global Warming Potential of gas $j$, TH is the considered time horizon, $R F_{j}$ denotes the global mean radiative forcing of gas $j, a_{j}$ is the radiative forcing per unit mass increase in atmospheric abundance of gas $j$ (radiative efficiency), $C_{j}(t)$ represents the timedependent abundance of gas $j$ and $r$ is the reference gas $\left(\mathrm{CO}_{2}\right)$.

The GWP of a gas represents the joint effect of two characteristics: the atmospheric lifetime of the gas and its relative effectiveness to absorb the thermal radiation from the atmosphere. The assumptions behind the concept of GWP are the following. First, it considers a fixed time horizon over which the effects of the different emissions are compared. Secondly, any discount rate to the greenhouse effect caused by the gas during the time horizon is applied, being null the effect of the gas at the completion of that period of time. It also assumes that GHGs concentration remains constant and, finally, that the impact caused by the gas is proportional to its radiative forcing.

Current IPCC estimates of GWPs values are based on time horizons of 20, 100 and 500 years. The establishment of a fixed time horizon to compare the effects of different GHGs emissions is a drawback of this measure, given the existence of short- and long-lived gases in the atmosphere. Thus, some climate scientists suggest that the separation between short- and long-lived gases could provide a better framework for the implementation of climate policies [50]. Another inconvenient of this measure is that GWPs are updated over time, incorporating

\footnotetext{
${ }^{6}$ Rasmussen [49] developed a methodology for comparing the risks caused by different GHGs emissions over a fixed time horizon.

${ }^{7}$ Radiative forcing is defined as the change in the balance between radiation coming into and going out of the atmosphere as a result of internal changes in the composition of the atmosphere. Thus, a positive (negative) radiative forcing tends to warm (cool) the Earth's surface [31].
} 
changes in atmospheric concentrations of GHGs as well as new scientific knowledge in this area. This calculation could cause an increasing economic emphasis on reducing emissions of short-lived gases like the methane, delaying the reduction of long-lived gases, in particular $\mathrm{CO}_{2}$. Thus, the problem of climate change could worsen ${ }^{8}$.

However, despite the fact that the limitations of the GWP encourage the search for alternatives to compare different $\mathrm{GHGs}^{9}$, most literature considers this measure as a benchmark to compare emissions. Thus, Manning et al. [50] state that the other measures should be considered as complementary rather than substitute.

\section{Methodology}

In this section, the methodology used in the multidimensional inequality analysis is detailed. Multidimensional inequality measures are additively decomposable by population groups allowing the study of inequality both between and within regions.

Consider a sample of $N$ countries where we want to study, jointly, $K$ dimensions related to climate change. These values are collected in the matrix $\mathbf{X}$, of dimension $N x K$ :

$$
\mathbf{X}=\left[\begin{array}{ccccc}
x_{11} & \ldots & x_{1 j} & \ldots & x_{1 K} \\
\vdots & & \vdots & & \vdots \\
x_{i 1} & \ldots & x_{i j} & \ldots & x_{i K} \\
\vdots & & \vdots & & \vdots \\
x_{N 1} & \ldots & x_{N j} & \ldots & x_{N K}
\end{array}\right]
$$

where each element of the matrix, $x_{i j}$, is the value of the dimension or variable $j$ of country $i$. In this paper, as we want to analyze the inequality in the global level of the four main GHGs emissions, the values $x_{i j}$ correspond to the emissions of $\mathrm{CO}_{2}, \mathrm{CH}_{4}, \mathrm{~N}_{2} \mathrm{O}$ and F-gases in each country, so that $K=4$. These emissions are measured in million tons of $\mathrm{CO}_{2}$-equivalent (MtCO2e) taking into account the GWPs of each gas.

\footnotetext{
${ }^{8}$ In this sense, because of preventing the atmospheric concentration of GHGs could lead to confusion when setting policies to achieve the stabilization in the long-term, the UNFCCC proposed freezing the GWPs values calculated in the Second Assessment Report of the IPCC [51].

${ }^{9}$ Other measures that have received special attention to measure the effect of different GHGs are the Global Damage Potential [52], the Global Cost Potential [53] and the Global Temperature Potential [54, 55]. In this line, Tol et al. [44] suggest that each measure is suitable for a specific perspective of climate change.
} 
In order to analyze the evolution of inequality, we consider the multidimensional inequality measures proposed by [2]. These measures are based on the concept of generalized entropy and they are defined as:

$$
G E M_{\gamma}(\mathbf{X})=\frac{1}{\gamma(1+\gamma)} \frac{1}{N} \sum_{i=1}^{N}\left[\left(\frac{s_{i}}{\bar{s}}\right)^{1+\gamma}-1\right], \quad \gamma \neq-1,0,
$$

where the $\gamma$ parameter represents the weight assigned to the different parts of the distribution. When $\gamma>0$ the countries which emit more GHGs emissions receive more weight, such that the higher the $\gamma$ value, the greater the weight given to these countries.

When $\gamma$ takes the values -1 -the least polluting countries received more weight- and 0 -it is assigned the same weight to all the parts of the distribution-, we are faced with the special cases of these measures, which are expressed respectively as:

$$
\begin{aligned}
& G E M_{-1}(\mathbf{X})=\frac{1}{N} \sum_{i=1}^{N} \log \left(\frac{\bar{s}}{s_{i}}\right), \\
& \operatorname{GEM}_{0}(\mathbf{X})=\frac{1}{N} \sum_{i=1}^{N} \frac{s_{i}}{\bar{s}} \log \left(\frac{s_{i}}{\bar{s}}\right) .
\end{aligned}
$$

Whatever the case, different dimensions are aggregated for each country using a generalized mean of order $-\beta$ :

$$
S_{i}=\left(\sum_{j=1}^{K} \delta_{j} x_{i j}^{-\beta}\right)^{-1 / \beta}, \quad i=1, \ldots, N,
$$

where $\bar{s}$ is the arithmetic mean of the values $s_{i}$.

Additionally, $\delta_{j}\left(j=1, \ldots, K, 0 \leq \delta_{j} \leq 1\right)$ and $\beta(-1 \leq \beta \leq \infty)$ are two parameters with a specific meaning. In particular, $\delta_{j}$ is the weight assigned to each variable $j$ and $\beta$ represents the elasticity of substitution among the dimensions considered.

As seen in the previous section, to compare the effect of GHGs emissions it is necessary to take into account their relative contribution to the greenhouse effect, as well as, the amount of emissions which each gas releases into the atmosphere. As all the emissions are expressed in $\mathrm{CO}_{2}$-equivalent using the 100-year GWPs published in the IPCC Second Assessment Report 
$(1996)^{10}$, the "damage" caused by each gas is collected in the elements of the matrix $\mathbf{X}$. Therefore, the weight assigned to each of the pollutants corresponds to the "amount" of each of them, that is, the share of the atmospheric concentration of each gas, measured in $\mathrm{CO}_{2}$ equivalent, in the year $2011^{11}$. Specifically, the $\delta$ parameter takes the value of 0.7394 for $\mathrm{CO}_{2} ; 0.0955$ for $\mathrm{CH}_{4} ; 0.1624$ for $\mathrm{N}_{2} \mathrm{O}$ and 0.0028 for F-gases ${ }^{12}$. Thus, the inequality measure contemplates the two characteristics which allow us to compare the emissions from different GHGs. Then, firstly, it is considered that $\beta=-1$, namely, there is perfect substitution among contaminants. However, considering the relative contribution to the greenhouse effect and the amount of each gas as the only factors taken into account to compare GHGs emissions is an assumption that restricts the existence of other agents. Consequently, in this paper we consider different substitution degrees among dimensions. So that, as $\beta$ parameter takes values above -1 , for example, 0.5 and 9 , the degree of substitution decreases ${ }^{13}$.

Multidimensional inequality indices used $\left(G E M_{\gamma}, G E M_{-1}\right.$ and $\left.G E M_{0}\right)$ are additively decomposable, which allows analyzing the between- and within-group inequality components. Considering the methodology proposed by Maasoumi [2] and Maasoumi and Nickelsburg [57], the index $G E M_{\gamma}$ supports the following decomposition:

$$
G E M_{\gamma}(\mathbf{X})=B_{\gamma}(\mathbf{X})+W_{\gamma}(\mathbf{X})
$$

where $B_{\gamma}(\mathbf{X})$ is the between-group inequality component whose expression is the following:

$$
B_{\gamma}(\mathbf{X})=f\left(\sum_{g=1}^{G} \frac{N_{g}}{N} h\left(\bar{s}^{g}, \bar{s}\right)\right),
$$

and $W_{\gamma}(\mathbf{X})$ is the within-group inequality component which can be express as:

$$
W_{\gamma}(\mathbf{X})=\sum_{g=1}^{G} w_{g} f\left(\frac{1}{N_{g}} \sum_{i \in g} h\left(s_{i}, \bar{s}^{g}\right)\right) .
$$

\footnotetext{
${ }^{10}$ Although the GWPs values were updated in the Third, Fourth and Fifth Assessment Report of the IPCC [29, 26, 32], the estimates of emissions from these reports continue using the GWPs from the Second Report of Assessment of the IPCC [51] in order to be consistent with the global reports of the UNFCCC.

${ }^{11}$ It was considered the concentration of GHGs in 2011 provided by the IPCC [32] because is the last year with available data.

12 The concentration of $\mathrm{CO}_{2}, \mathrm{CH}_{4}, \mathrm{~N}_{2} \mathrm{O}$ and F-gases in 2011 was 391000000, 1803000, 324000 and 210.04 parts per trillion, respectively.

${ }^{13}$ In this type of analysis are often considered various values for $\beta$ in order to observe the sensitivity of the results to the variation of this parameter [56].
} 
where $G$ is the number of regions; $N_{g}$ is the number of countries which belong to region $g$ $(g=1, \ldots, G) ; w_{g}$ is the weight attached to region $g$. In addition, $f$ and $h$ functions are continuous functions, $f$ strictly increasing, whose arguments are specified in Table 1.

Table 1 shows the elements of these indexes for the different values of $\gamma$ parameter, where $S_{i}=\left(\sum_{j=1}^{K} \delta_{j} X_{i j}^{-\beta}\right)^{-1 / \beta}, i \in g ; \bar{s}$ is the arithmetic mean of the values $s_{i}$ and $\bar{s}^{g}$ is the arithmetic mean of the values $s_{i}$ over the individuals in region $g$.

Table 1. Elements of the between- and within-group inequality components

\begin{tabular}{cccc}
\hline Gamma & $\boldsymbol{f ( y )}$ & $\boldsymbol{h}(\boldsymbol{t} ; \overline{\boldsymbol{t}})$ & $\boldsymbol{w}_{\boldsymbol{g}}, \boldsymbol{g}=\mathbf{1}, \ldots, \boldsymbol{G}$ \\
\hline $\boldsymbol{\gamma} \neq \mathbf{0 , - 1}$ & $\frac{y}{\gamma(1+\gamma)}$ & $\left(\frac{t}{\bar{t}}\right)^{1+\gamma}-1$ & $\frac{N_{g}}{N}\left(\frac{\bar{s}^{g}}{\bar{s}}\right)^{1+\gamma}$ \\
$\gamma=-\mathbf{1}$ & $y$ & $\log \left(\frac{t}{\bar{t}}\right)$ & $\frac{N_{g}}{N}$ \\
$\boldsymbol{\gamma}=\mathbf{0}$ & $y$ & $\frac{t}{\bar{t}} \log \left(\frac{t}{\bar{t}}\right)$ & $\frac{N_{g} \bar{s}^{g}}{N \bar{s}}$ \\
\hline
\end{tabular}

Source: Gigliariano and Mosler [56].

\section{Data and results}

The data used in this analysis have been taken from the Climate Analysis Indicators Tool database, developed by the World Resources Institute [1]. As it has a large number of climate indicators, this tool is suitable for analyzing issues related to climate change. Furthermore, this database allows compare the emissions from various greenhouse gases ${ }^{14}$.

The variables under study are the emissions of the four main GHGs: $\mathrm{CO}_{2}, \mathrm{CH}_{4}, \mathrm{~N}_{2} \mathrm{O}$ and Fgases, measured in $\mathrm{MtCO}_{2} \mathrm{e}$ using the 100-year GWPs published in the IPCC [51]. We used the annual emission indicator which shows the amount of GHGs emitted by a country during

\footnotetext{
${ }^{14}$ Although GHGs emissions data comes from various nongovernmental sources -International Energy Agency [58], Carbon Dioxide Information Analysis Center [59], United States Environmental Protection Agency [60], Energy Information Administration [61] and Food and Agriculture Organization of the United Nations [62]-, such inventories are comparable since they are made using the method proposed by the IPCC [63, 64].
} 
a given year. These variables are studied across all the countries with available information from 1990 to $2011^{15}$.

In this section, we analyze the multidimensional inequality considering the four most important gases $-\mathrm{CO}_{2}, \mathrm{CH}_{4}, \mathrm{~N}_{2} \mathrm{O}$ and F-gases- emissions, using the measures described in Section 3. As specified previously, these measures include three parameters. The $\delta$ parameter, which attaches the weight to each GHG in the overall index, has been set considering the proportion of emissions that represented each pollutant in 2011. For the $\beta$ parameter, we have considered the values $-1,0.5$ and 9 which represent different substitution degrees among the polluting gases included in the analysis. Finally, $\gamma$ parameter has been set to $1.5,-1$ and 0 , allowing us to study the sensibility of the results to variations in the weight assigned to the different parts of the distribution.

In Table 2 we present the multidimensional inequality indices for the four main pollutants over the period 1990-2011. The inequality multidimensional indexes show different behavior patterns depending on the weight given to the different parts of the distribution.

Table 2. Evolution of inequality in $\mathrm{CO}_{2}, \mathrm{CH}_{4}, \mathrm{~N}_{2} \mathrm{O}$ and F-gases emissions (1990-2011)

\begin{tabular}{|c|c|c|c|c|c|c|c|c|c|}
\cline { 2 - 10 } \multicolumn{1}{c|}{} & \multicolumn{3}{|c|}{ GEM $_{\mathbf{1 . 5}}$} & \multicolumn{3}{c|}{ GEM $_{-\mathbf{1}}$} & \multicolumn{3}{c|}{ GEM $_{\mathbf{0}}$} \\
\hline Year & $\boldsymbol{\beta}=\mathbf{- 1}$ & $\boldsymbol{\beta}=\mathbf{0 . 5}$ & $\boldsymbol{\beta}=\mathbf{9}$ & $\boldsymbol{\beta}=-\mathbf{1}$ & $\boldsymbol{\beta}=\mathbf{0 . 5}$ & $\boldsymbol{\beta}=\mathbf{9}$ & $\boldsymbol{\beta}=-\mathbf{~ 1}$ & $\boldsymbol{\beta}=\mathbf{0 . 5}$ & $\boldsymbol{\beta}=\mathbf{9}$ \\
\hline 1990 & 0.5509 & 0.4834 & 5.3077 & 0.2328 & 0.2092 & 0.9875 & 0.1765 & 0.1611 & 0.6281 \\
\hline 1992 & 0.6066 & 0.4468 & 4.8157 & 0.2241 & 0.1930 & 0.8228 & 0.1780 & 0.1502 & 0.5740 \\
\hline 1994 & 0.6713 & 0.4733 & 3.7813 & 0.2305 & 0.1896 & 0.7526 & 0.1866 & 0.1516 & 0.5253 \\
\hline 1997 & 0.6897 & 0.4744 & 2.4135 & 0.2239 & 0.1753 & 0.5985 & 0.1843 & 0.1453 & 0.4271 \\
\hline 2005 & 0.8341 & 0.3915 & 0.8174 & 0.2215 & 0.1538 & 0.3528 & 0.1911 & 0.1275 & 0.2377 \\
\hline 2009 & 0.6811 & 0.3863 & 0.6197 & 0.2096 & 0.1435 & 0.3117 & 0.1792 & 0.1199 & 0.2020 \\
\hline 2011 & 0.6692 & 0.4068 & 0.6021 & 0.2114 & 0.1443 & 0.3068 & 0.1797 & 0.1215 & 0.1986 \\
\hline
\end{tabular}

When more weight is attached to the emissions transfers between the most polluting countries $(\gamma=1.5)$, it is observed an increasing pattern in terms of inequality from 1990 to 2011 if the substitution degree among gases is perfect $(\beta=-1)$. Under this assumption, the maximum level of inequality is reached in 2005 and, since then, inequality declines. It is noted that such

\footnotetext{
${ }^{15}$ We start our research in the year 1990 because in that year the negotiations on a global convention began. Then we analyze the years 1992, 1994, 1997, 2005 and 2009 because in these years took place important advances for achieving an international treatment. Thus, in 1992 and 1994, the UNFCCC was adopted and came into force, respectively; in 1997 and 2005, the Kyoto Protocol was adopted and came into force, respectively; and in 2009, the COP-15 was celebrated in Copenhagen. Finally, we study the year 2011 which is the last year for which the WRI provides information on the variables under study.
} 
descent coincides with the entry into force of the Kyoto Protocol. Meanwhile, when the substitution degree among pollutants decreases $(\beta=0.5$ and $\beta=9)$, it is perceived a fall in GHGs emissions inequality, being much more accentuated in the latter case. Specifically, we observe the biggest fall in inequality when $\gamma$ and $\beta$ take the values 1.5 and 9, respectively.

In contrast, under the scenarios where the changes in the least polluting countries prevail on the rest of the distribution $(\gamma=-1)$, the results show a decrease in the concentration of GHGs emissions during the period, regardless of the substitution degree among pollutants. Although it is true that, in relative terms, such reduction is greater as the substitution degree among pollutants decreases. Thus, when we assume perfect substitution among gases $(\beta=-1)$ the decline is quantified in 9 percent, whereas, inequality is reduced by about 69 percent when $\beta$ is set to 9 .

Finally, when all countries are equally weighted $(\gamma=0)$, inequality in GHGs emissions suffers a little increase (by about 2 percent) over the period 1990-2011 when the elasticity of substitution among gases is perfect $(\beta=-1)$. However, the results show a decreasing pattern in terms of inequality as the substitution degree among pollutants decreases ( $\beta=0.5$ and $\beta=9$ ). In this context, as happens in the previous cases, the disparities decline on the basis of the value of the $\beta$ parameter in a way that, a greater reduction occurs as the substitution degree among GHGs decreases.

In order to evaluate the consistency of our results we have also evaluated the world inequality in GHGs emissions using the Gini index. It is defined as the area between the line at 45 degrees and the Lorenz curve divided by the area of the triangle which is below the diagonal line. It ranges from 0 -perfect equality- to 1 -perfect inequality-. The left panel of Figure 1 shows the evolution of the Gini coefficient for per-capita GHGs emissions from 1990 to 2011. The Gini index is computed giving the same weight to all the countries and assuming different substitution degrees among pollutants: the blue dashed-dotted line represents a perfect substitution degree $(\beta=-1)$, the red dotted line a high substitution degree $(\beta=0.5)$ and the green dashed line a low substitution degree $(\beta=0.9)$.

During the period 1990-2011, the evolution of the Gini coefficient for GHGs emissions is similar to the one experienced by the GEM index but when the elasticity of substitution among gases is high $(\beta=9)$. In the latter case, the GEM index shows a decreasing trend while the Gini index remains constant. Despite this small difference, in both indexes the lowest and highest inequality level is observed when $\beta=0.5$ and $\beta=9$, respectively. 
Figure 1. (Left panel) Evolution of the Gini index for per-capita GHGs emissions from 1990 to 2011. (Right panel) Lorenz plots for per-capita GHGs emissions when $\beta=-1$ in 1990 and 2011.

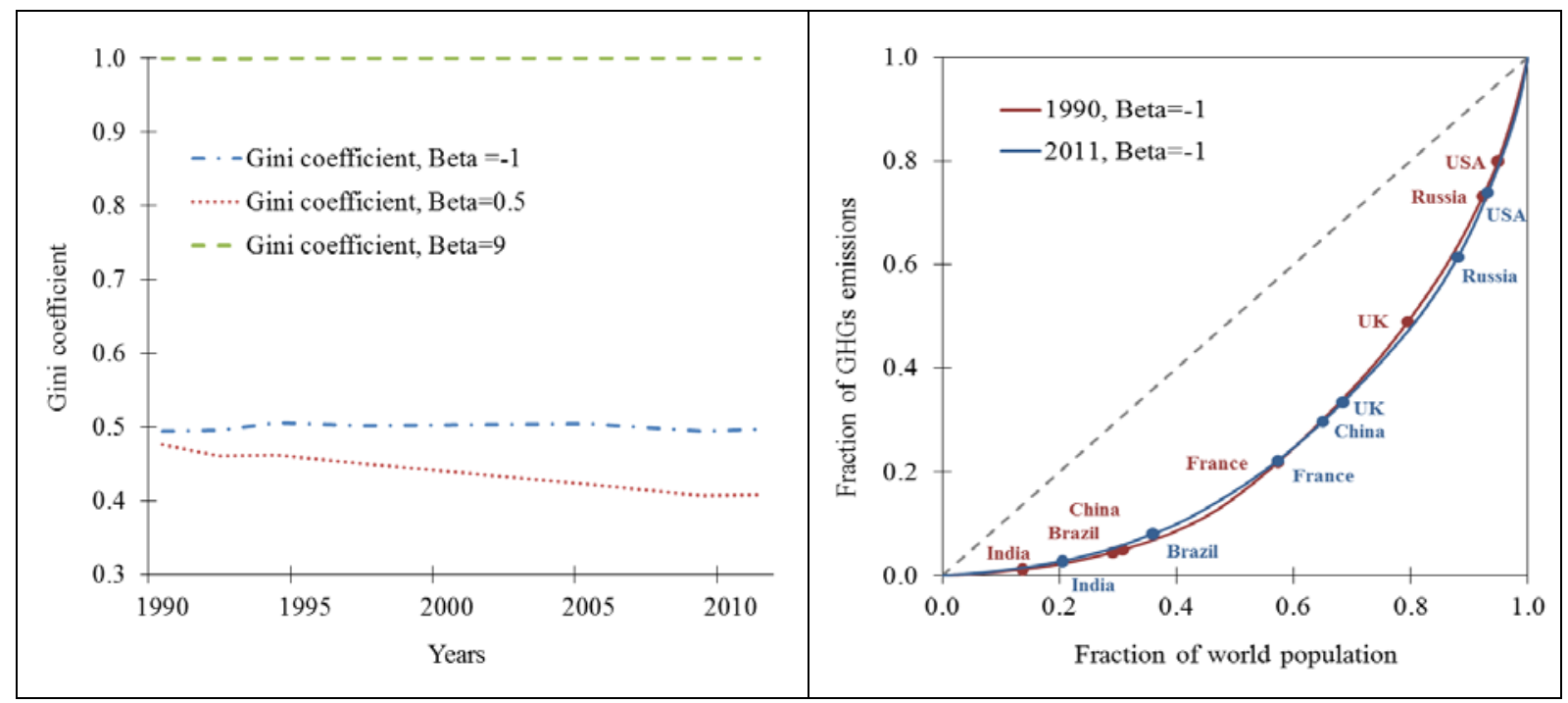

Meanwhile, when the substitution degree among gases is perfect $(\beta=-1)$ the value of the Gini index is around 0.5, being close to the theoretical equilibrium of an exponential distribution [55]. The Lorenz plots when $\beta=-1$ in 1990 and 2011 are shown in the right panel of Figure 1. In addition, we have included some results for different countries. Again, we observe that per-capita GHGs emissions are exponential distributed in both years. Over this time period, the Lorenz plots have moved up just a little bit, evolving to a short more equal distribution. Regarding the countries order, it should be highlighted the growth of GHGs emissions in China which is in accordance with its recent and fast economic growth.

Going back to the inequality analysis based on the GEM index, it is noted that the multidimensional indices used in this paper can be additively decomposed by population groups. In other words, this decomposition allows studying which part of total inequality can be attributed to differences between groups and what to disparities within a group. While inequality between regions only considers the differences between average inequalities of each region, the second component highlights the inequality between the countries, which belong to the same region.

To analyze the decomposition of the generalized entropy measures in their interregional and intraregional components, in this work we have chosen to divide the population into different subgroups considering the amount of GHGs emissions released into the atmosphere by each 
country in $1990^{16}$. Thus, starting from a sample of 117 countries, which is ordered from the lowest emitter country to the highest one, we built 10 groups, each one containing a 10 percent of observations. In such a way, the first (last) group of countries is formed by the 10 percent of countries that emit less (more) GHGs emissions in 1990.

Figure 2 shows the results of the decomposition of multidimensional indices by population groups. The solid line represents the total inequality value shown in Table 2, the short-dashed line exhibits the within-group inequality component and the large-dashed displays the between-group inequality. According to the results, both components contributed to the change in overall inequality from 1990 to 2011. This aspect supports the choice for the presented methodology, which considers the decomposition of total inequality in both components.

The between-group inequality component shows a declining trend from 1990 to 2011, regardless of the weight given to the different parts of the distribution and the substitution degree among pollutants. As in the global distribution of inequality case, the largest decline in inequality between regions takes place when is given more importance to the emissions transfers between the most polluting countries $(\gamma=1.5)$ and the elasticity of substitution among gases is low $(\beta=9)$. However, if we assume a perfect or high substitution degree among pollutants $(\beta=-1$ and $\beta=0.5)$, the biggest inequality decrease occurs when all countries are equally weighted $(\gamma=0)$. We also detect a greater reduction in the inequality associated with this component as the substitution degree among gases decreases.

As for the within-group inequality component, we can conclude that its evolution along the period depends on the substitution degree among pollutants. Thus, when we assume a low substitution degree among gases $(\beta=9)$, the inequality trend is decreasing; holding the opposite tendency as the $\beta$ parameter takes smaller values. In addition, while we observe the largest descent when more weight is attached to the emissions transfers between the most polluting countries $(\gamma=1.5)$, the highest enlargement happens when all countries receive the same importance $(\gamma=0)$.

\footnotetext{
${ }^{16}$ The classification of the countries can be found in the Appendix.
} 
Figure 2. Evolution of the decomposition of total inequality in $\mathrm{CO}_{2}, \mathrm{CH}_{4}, \mathrm{~N}_{2} \mathrm{O}$ and F-gases emissions in the between- and within inequality components using the $G E M_{\gamma}$ index (1990-2011)

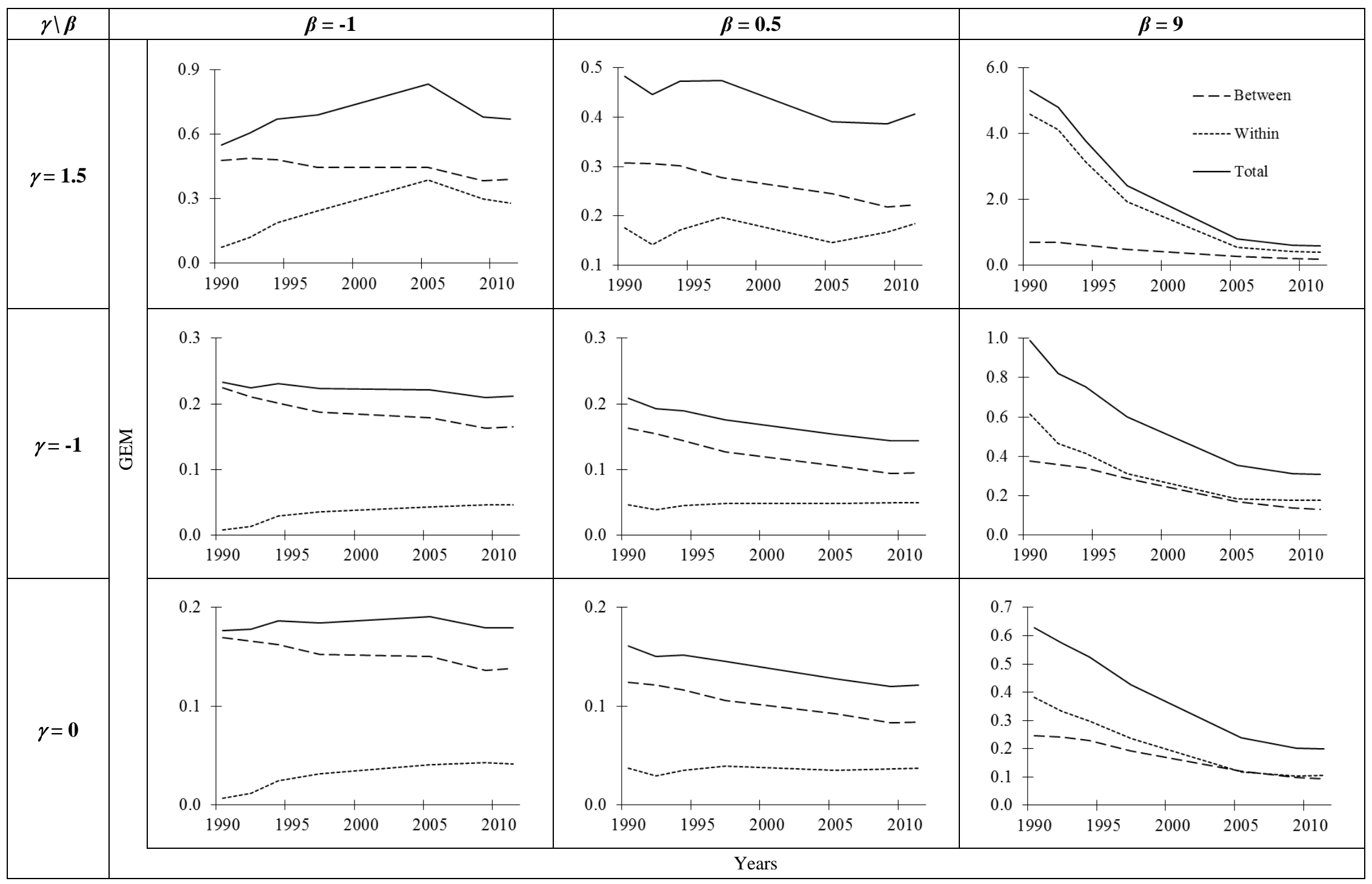


As seen in Figure 2, the evolution of the weight of both inequality indices does not depend on the $\gamma$ parameter; however, it is affected by the assumptions made in relation to the $\beta$ parameter. Thus, while the interregional component is a predominant factor in the scenarios where the substitution degree among GHGs is perfect or high $(\beta=-1$ and $\beta=0.5$ ), the intraregional inequality receives a greater weight when a lower substitution degree among gases is admitted $(\beta=9)$. Despite the fact that, depending on the assumptions made about $\beta$, one or another component prevails over global inequality in GHG emissions, it should be noted that, in all cases, the predominant component has been progressively reducing its weight in total inequality in favor of the other element.

\section{Sensitivity analysis of inequality evolution}

To complete the previous study of inequality, in this section, we carry out two different sensitivity analyses. First, we study the evolution of inequality in $\mathrm{CO}_{2}, \mathrm{CH}_{4}, \mathrm{~N}_{2} \mathrm{O}$ and F-gases emissions, paying special attention to the substitution degree among pollutants. Secondly, we analyze the relative importance of the between- and within-group inequality components in global inequality.

Figure 3 shows the variation of the GEM index to the $\beta$ parameter ${ }^{17}$ in the three scenarios defined by the gamma parameter: when all countries are equally weighted $(\gamma=$ 0 ), when more weight is attached to the emissions transfers between the most polluting countries $(\gamma>0)$ and when the changes in the least polluting countries prevail on the rest of the distribution $(\gamma<0)^{18}$. In the three cases, the time period ranges from 1990 to 2011.

When all the countries are equally weighted $(\gamma=0)$, inequality increases by about 2 percent when the substitution degree among gases is perfect $(\beta=-1)$. In addition, under this elasticity assumption, the maximum increment of inequality is reached in the year 2005. Inequality decreases from the value $\beta=-0.6$, in such a way that the minimum level is reached in 2011 when $\beta=9$. It should be noted that the inequality decrease slows down from $\beta=2$, being the effect of the substitution degree on the inequality decrease much lower.

\footnotetext{
17 The $\beta$ parameter ranges from -1 to 9 by increments of 0.01 .

${ }^{18}$ In this sensitivity analysis, we choose three values for the $\gamma$ parameter $(\gamma=0,1.5$ and -1 ), so that, each one of them represents one of the scenarios mentioned above, respectively.
} 
Figure 3. Growth rate of inequality in $\mathrm{CO}_{2}, \mathrm{CH}_{4}, \mathrm{~N}_{2} \mathrm{O}$ and F-gases emissions using the $G E M_{\gamma}$ index $(1990-2011,1990=100)$

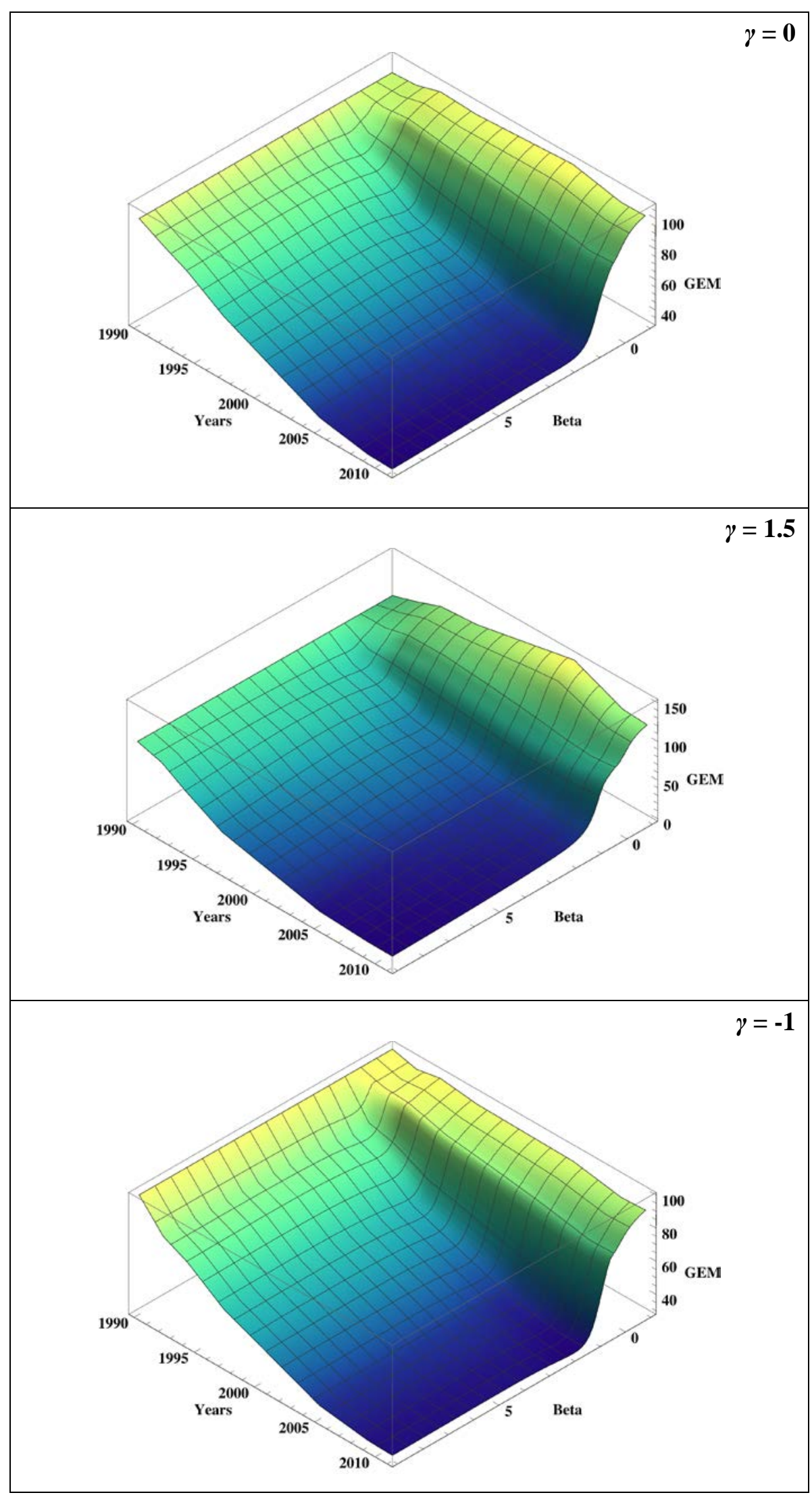


If we attach more weight to the emissions transfers between the most polluting countries $(\gamma=1.5)$, the maximum level of inequality is always reached in the year 2005 when $\beta$ parameter values are low $(\beta<0)$. In particular, the highest level is observed when the substitution degree among gases is perfect $(\beta=-1)$. When $\beta>0$, the minimum level of inequality is generally reached in 2009. However, as happens in the previous case, the lowest level of inequality occurs in the year 2011 when $\beta$ is set to 9. It should be highlighted that, considering all cases together, the maximum and minimum levels of inequality take place when $\gamma=1.5$.

Supposing that the changes in the least polluting countries prevail on the rest of the distribution $(\gamma=-1)$, the results indicate that the maximum level of inequality is reached in the reference period (year 1990), irrespective of $\beta$ parameter value. Under this assumption, we observe that inequality is reduced from $\beta=-1$ to $\beta=2$, showing the opposite trend until $\beta=5$. Finally, from $\beta=5$ onwards, inequality decrease slightly.

Our analysis reveals a general behavior pattern: the elasticity of substitution plays an important role in the variation of inequality. Thus, the greater substitution degree among gases, the lower inequality level. As we have seen before, the GWP depends on the time horizon, the discount rate and the radiative forcing assumed. In this sense, the dependence between the increasing inequality trend and the parameter value beta may be due to the existence of characteristics which had been omitted in the computation of the GWP.

Figure 4. Evolution of the relative importance of the within-group inequality component in total inequality, $W_{\gamma}(\mathrm{X}) / \operatorname{GEM}_{\gamma}(\mathrm{X}),(1990-2011)$

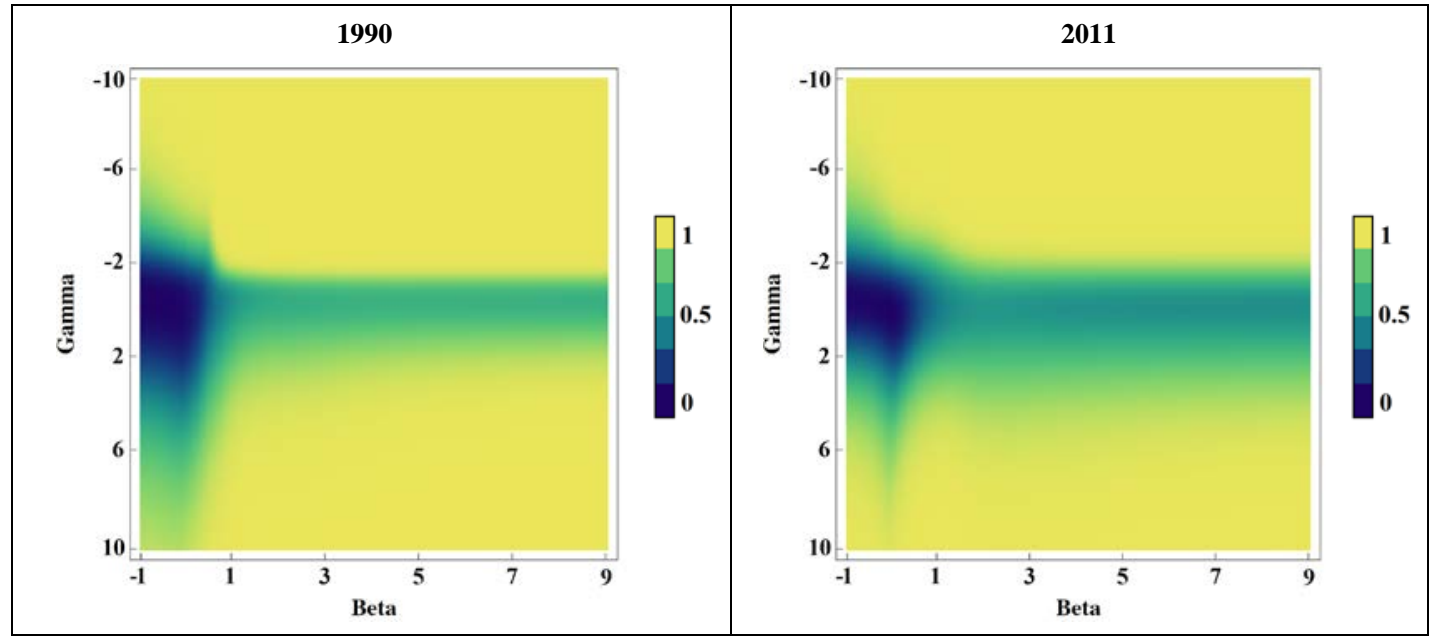


Figure 4 presents the relative importance of the between- and within-group inequality components for several combinations of the $\gamma$ and $\beta$ parameters ${ }^{19}$. This approach allows us to analyze the weight of the components in total inequality without assuming a specific substitution degree among contaminants and level of aversion to inequality.

In both graphs, the within-group inequality component predominates in most combinations of parameters. Even though, when we attribute the same weight to all countries $(\gamma=0)$, the between-group inequality component prevails if the substitution degree among gases is perfect or very high. Under this same context $(\gamma=0)$, the proportion of total inequality which is explained by each component seems to be similar when a lower substitution degree among gases is admitted.

Comparing both years -1990 and 2011-, we can conclude again that the dominant component in 1990 has reduced its importance in total inequality in favor of the no predominant element.

\section{Conclusions and discussion}

In this paper we analyze inequality in the distribution of the four main GHGs emissions $-\mathrm{CO}_{2}, \mathrm{CH}_{4}, \mathrm{~N}_{2} \mathrm{O}$ and F-gases- from a multidimensional perspective in the period 19902011. For this purpose, we use the generalized entropy measures proposed by Maasoumi [2], which allows analyzing the between- and within-group inequality components.

The data used in this analysis have been extracted from the Climate Analysis Indicators Tool database, which is updated by the World Resources Institute. The emissions of the four main GHGs are expressed in million metric tons of $\mathrm{CO}_{2}$-equivalent using the 100year GWPs values published in the IPCC’s Second Assessment Report of 1996.

The multidimensional inequality indices show that the results vary, during the period of study, according to the weight assigned to the different parts of the distribution. When more weight is attached to the emissions transfers between the most polluting countries, it is observed an increasing inequality trend over the whole period when the substitution degree among gases is perfect or very high. Meanwhile, when the substitution degree

\footnotetext{
${ }^{19}$ The $\beta$ parameter ranges from -1 to 9 by increments of 0.01 while, the $\gamma$ parameter ranges from -10 to 10 by increments of 0.5 .
} 
among pollutants decreases, it is perceived a reduction in GHGs emissions inequality. The previous pattern is repeated when all countries are equally weighted.

In contrast, when changes in the least polluting countries prevail on the rest of the distribution, the results show a decrease in the concentration of GHGs emissions during the period 1990-2011, regardless of the substitution degree among pollutants.

To analyze the decomposition of the generalized entropy measures in their interregional and intraregional components, we have divided the countries into different subgroups considering the amount of GHGs emissions released into the atmosphere by each country in 1990. The between-group inequality component shows a declining trend during the period 1990-2011, regardless of the weight given to the different parts of the distribution and the substitution degree among pollutants. The behavior of the withingroup inequality component depends on the substitution degree among gases. Thus, when we assume a low substitution degree among them, the inequality trend is decreasing; holding the opposite tendency as the $\beta$ parameter takes smaller values.

Analyzing, jointly, both inequality indices, we observe that, while the interregional component is a predominant factor in the scenarios where the substitution degree among GHGs is perfect or high, inequality within regions receives a greater weight when a lower substitution degree among gases is admitted. However, in all cases, the predominant component has been progressively reducing its weight in total inequality in favor of the other element.

To complete the study of inequality, we have made two different sensitivity analyses which confirm the results obtained in the previous section.

In relation to environmental policies it can be noted the following. On the one hand, the compromise reached in the UNFCCC in 1992, to adopt measures to stabilize GHGs emissions, may be one of the causes that lie behind the declining inequality trend when is given more importance to the emissions transfers between the most polluting countries. However, there are arguments in the literature to make a distinction between equality and fairness. Because of an equal distribution in not necessarily fair, Venkatasubramanian [66] supports that a fair distribution is the one that maximizes entropy.

On the other hand, it should be also noted the similarity of the results obtained when the changes in the most polluting countries prevail on the rest of the distribution and when 
all countries are equally weighted. Thus, although from a point of view of climate policy may seem more interesting the first case, the consistency in the results of both scenarios means that we should give the green light to the use of other inequality measures which do not support assigning a different weight to the different parts of the distribution.

It is expected that the weight of the interregional and intraregional inequality components equalize over time because they continued a trend in which the predominant component is losing importance in favor of the other element.

This analysis does have some limitations. On one side, the GHGs emissions used in this paper are measured using the production-based National Emissions Inventory. Thus, replicating the same study considering the emissions calculated using the consumptionbased National Emissions Inventory could be a sensitive analysis of our results. On the other side, this study does not provide any kind of information about inequality within each region. In this line, the application of this analysis to a specific region could be of great interest for policy making.

Nevertheless, this work represents one of the first attempts to study the evolution of GHGs emissions. Future research should be addressed to expand and complete this work. In this sense, the future data availability will allow investigate the evolution of world inequality in GHGs emissions considering a greater number of them which, undoubtedly, will be a valuable tool for implementing policies to reduce these emissions. Also, a similar study covering a longer period will be able to show the effects of recent international agreements on inequality.

As countries refuse to act alone in response to global climate change, international cooperation is needed. Despite the fact that per-capita emissions are commonly higher in wealthier countries, there are important exceptions. For instance, some middleincome developing economies have per-capita emissions levels close to those of richer developed countries. Given the wide variety of countries with different characteristics and similar per-capita emissions profiles, one-size-fits-all strategies are unlikely to be successful in advancing international cooperation on climate change. In this sense, a polarization analysis from this same multidimensional perspective will identify the emergence of poles in the global distribution of GHGs emissions. 


\section{Acknowledgements}

The authors thank the Ministerio de Economía y Competitividad (Project ECO201348326-C2-2-P) and the Ministerio de Educación, Cultura y Deporte (FPU13/02155) for the partial support of this work. They are grateful for the constructive suggestions provided by the editor and the reviewers, which greatly improved the paper.

Appendix. Classification of the analyzed countries

Group I: Bangladesh, Cambodia, El Salvador, Ghana, Guatemala, Kenya, Myanmar, Nepal, Pakistan, Sri Lanka, Vietnam, Yemen.

Group II: Democratic Republic of the Congo, Costa Rica, Cote d'Ivoire, Dominican Republic, Honduras, India, Indonesia, Morocco, Nicaragua, Nigeria, Peru, Philippines.

Group III: Albania, Bolivia, Brazil, Cameroon, Colombia, Ecuador, Egypt, Panama, Thailand, Tunisia, Zimbabwe.

Group IV: Algeria, Angola, Chile, China, Jamaica, Lebanon, Mexico, Syria, Tajikistan, Turkey, Uruguay, Zambia.

Group V: Argentina, Bosnia and Herzegovina, Croatia, Cuba, Iran, Iraq, Jordan, Republic of Korea, Kyrgyzstan, Republic of Macedonia, Malaysia, Portugal.

Group VI: Armenia, Cyprus, France, Hungary, People's Republic of Korea, Mongolia, Spain, Sweden, Switzerland, Uzbekistan, Venezuela.

Group VII: Austria, Azerbaijan, Georgia, Greece, Iceland, Israel, Italy, Latvia, Norway, Romania, Slovenia, South Africa.

Group VIII: Bulgaria, Ireland, Japan, Lithuania, Moldova, New Zealand, Oman, Poland, Serbia, Singapore, United Kingdom.

Group IX: Belarus, Belgium, Denmark, Finland, Germany, Libya, Netherlands, Saudi Arabia, Slovakia, Trinidad and Tobago, Turkmenistan, Ukraine.

Group X: Australia, Bahrain, Brunei, Canada, Czech Republic, Estonia, Kazakhstan, Luxembourg, Qatar, Russia, United Arab Emirates, United States. 


\section{References}

[1] WRI -World Resources Institute-, Climate Analysis Indicators Tool, Version 9.0, World Resources Institute, Washington DC, USA, 2014 [Available at: http://cait.wri.org]

[2] E. Maasoumi, The Measurement and Decomposition of Multidimensional Inequality, Econometrica 54 (1986) 991-997.

[3] L. Gao, Evolution of consumption distribution and model of wealth distribution in China between 1995 and 2012, Physica A 429 (2015) 76-86.

[4] A.A. Drăgulescu, V.M. Yakovenko, Exponential and power-law probability distributions of wealth and income in the United Kingdom and the United States, Physica A 299 (2001a) 213-221.

[5] A. Banerjee, V.M. Yakovenko, T. Di Matteo, A study of the personal income distribution in Australia, Physica A 370 (2006) 54-59.

[6] M. Jagielski, R. Kutner, Modelling of income distribution in the European Union with the Fokker-Planck equation, Physica A 392 (2013) 2130-2138.

[7] B.K. Chakrabarti, A. Chakraborti, S.R. Chakravarty, A. Chatterjee, Econophysics of Income and Wealth Distributions, Cambridge University Press, Cambridge, UK, 2013.

[8] A. Ghosh, N. Chattopadhyay, B.K. Chakrabarti, Inequality in societies, academic institutions and science journals: Gini and k-indices, Physica A 410 (2014) 3034.

[9] J. Inoue, A. Ghosh, A. Chatterjee, B.K. Chakrabarti, Measuring social inequality with quantitative methodology: Analytical estimates and empirical data analysis by Gini and k indices, Physica A 429 (2015) 184-204.

[10] X. Cao, Climate change and energy development: implications for developing countries, Resources Policy 29 (2003) 61-67.

[11] United Nations, Kyoto Protocol to the United Nations Framework Convention on Climate Change, 1998 [Available at: http://unfccc.int/resource/docs/convkp /kpeng.pdf] 
[12] UNFCCC -United Nations Framework Convention on Climate Change -Report of the Intergovernmental Negotiating Committee for a Framework Convention on Climate Change on the work of the Second Part of Its Fifth Session, celebrated in New York from 30 April to 9 May 1992, United Nations, New York, USA, 1992.

[13] M.T. Heil, Q.T. Wodon, Inequality in $\mathrm{CO}_{2}$ emissions between poor and rich countries, Journal of Environment and Development 6 (1997) 426-452.

[14] M.T. Heil, Q.T. Wodon, Future inequality in $\mathrm{CO}_{2}$ emissions and the impact of abatement proposals, Environmental and Resource Economics 17 (2000) 163181.

[15] F. Hedenus, C. Azar, Estimates of trends in global income and resource inequalities, Ecological Economics 55 (2005) 351-364.

[16] J.W. Sun, The decrease in the difference of energy intensities between OECD countries from 1971 to 1998, Energy Policy 30 (2002) 631-635.

[17] V. Alcántara, J.A. Duro, Inequality of energy intensities across OECD countries: a note. Energy Policy 32 (2004) 1257-1260.

[18] E. Padilla, A. Serrano, Inequality in $\mathrm{CO}_{2}$ emissions across countries and its relationship with income inequality: a distributive approach, Energy Policy 34 (2006) 1762-1772.

[19] R. Ezcurra, Is there cross-country convergence in carbon dioxide emissions? Energy Policy 35 (2007) 363-1372.

[20] L. Groot (2010), Carbon Lorenz curves, Resource and Energy Economics 32 (2010) 45-64.

[21] N. Cantore, E. Padilla, Equality and $\mathrm{CO}_{2}$ emissions distribution in climate change integrated assessment modeling, Energy 35 (2010) 298-313.

[22] T.O. Mahony, Decomposition of Ireland's carbon emissions from 1990 to 2010: An extended Kaya identity, Energy Policy 59 (2013) 573-581.

[23] L. Remuzgo, J.M. Sarabia, Desigualdad en la distribución mundial de emisiones de $\mathrm{CO}_{2}$ por sectores: descomposición y estudio de sensibilidad, Estudios de Economía Aplicada 31 (2013) 65-92. 
[24] S. Lawrence, Q. Liu, M. Yakovenko, Global inequality in energy consumption from 1980 to 2010, Entropy 15 (2013) 5565-5579.

[25] WMO -World Meteorological Organization-, Greenhouse Gas Bulletin - N8: The State of Greenhouse Gases in the Atmosphere Based on Global Observations through 2012, 2013.

[26] IPCC -Intergovernmental Panel on Climate Change-, Cambio climático 2007: Informe de síntesis, Contribución de los Grupos de trabajo I, II y III al Cuarto Informe de evaluación del Grupo Intergubernamental de Expertos sobre el Cambio Climático, R.K. Pachauri, A. Reisinger, A. (Directors), IPCC, Ginebra, Suiza, 2007a.

[27] U.S. Department of State, Projected Greenhouse Gas Emissions, in: Fourth Climate Action Report to the UN Framework Convention on Climate Change, U.S. Department of State, Washington DC, USA, 2007.

[28] USEPA -U.S. Environmental Protection Agency-, Global Anthropogenic NonCO2 Greenhouse Gas Emissions: 1990-2030, U.S. Environmental Protection Agency, Office of Atmospheric Programs, Washington DC, USA, 2012a. [Available at: http://www.epa.gov/climatechange/Downloads/EPAactivities/ EPA_Global_NonCO2_Projections_Dec2012.pdf]

[29] IPCC -Intergovernmental Panel on Climate Change-, Technical Summary: A Report Accepted by Working Group I of the IPCC but not approved in detail, Product resulting from The Third Assessment Report of Working Group I of the IPCC, January, 2001 [Available at: http://www.ipcc.ch/pdf/assessmentreport/ar5/wg1/drafts/fgd/WGIAR5_WGI-12Doc2b_FinalDraft_Technical Summary.pdf]

[30] USEPA -U.S. Environmental Protection Agency-, Global Mitigation of Non-CO 2 Greenhouse Gases, U.S. Environmental Protection Agency, Office of Atmospheric Programs, Washington DC, USA, 2006 [Available at: http://www.epa.gov/climatechange/Downloads/EPAactivities/GlobalMitigationF ullReport.pdf] 
[31] IPCC -Intergovernmental Panel on Climate Change-, Climate Change 2007: The Physical Science Basis, Contribution of Working Group I to the Fourth Assessment Report of the IPCC, S. Solomon, D. Qin, M. Manning, Z. Chen, M. Marquis, K.B. Averyt, M. Tignor, H.L. Miller (Eds.), Cambridge University Press, Cambridge, UK, New York, USA, 2007b.

[32] IPCC -Intergovernmental Panel on Climate Change--, Climate Change 2013: The Physical Science Basis, Contribution of Working Group I to the Fifth Assessment Report of the IPCC, T.F. Stocker, D. Qin, G.K. Plattner, M. Tignor, S.K. Allen, J. Boschung, A. Nauels, Y. Xia, V. Bex, P.M. Midgley (Eds.), Cambridge University Press, Cambridge, UK, New York, USA, 2013.

[33] I. Kolstad, A. Wiig, Testing The Pearl Hypothesis: Natural resources and trust, Resources Policy 37 (2012) 358-367.

[34] H. Theil, Economics and Information Theory, North Holland, Amsterdam, Holland, 1967.

[35] A.F. Shorrocks, Inequality decomposition by factor components, Econometrica 50 (1982) 193-211.

[36] A.F. Shorrocks, Inequality decomposition by population sub-groups, Econometrica 52 (1984) 1369-1386.

[37] F.A. Cowell, Measuring inequality, Oxford University Press, Oxford, UK, 2011.

[38] J. Burbea, C.R. Rao, Entropy Differential Metric, Distance and Divergence Measures in Probability Spaces: A Unified Approach, Journal of Multivariate Analysis 12 (1982a) 575-596.

[39] J. Burbea, C.R. Rao, On the Convexity of Some Divergence Measures Based on Entropy Functions, IEEE Transactions on Information Theory 28 (1982b) 489495.

[40] C.E. Shannon, A mathematical Theory of Communication, The Bell System Technical Journal 27 (1948) 379-423, 623-656.

[41] L. Boltzmann, Lectures on Gas Theory (English translation by S.G. Brush), Dover, New York, USA, 1995 (Originally published under the title Vorlesungen über Gastheorie by J.A. Barth, Leizpig - Part I, 1896; Part II, 1898). 
[42] J.W. Gibbs, Elementary Principles of Statistical Mechaniscs, Yale University Press, New Haven, CT, USA, 1902.

[43] M. Planck, On the Law of Distribution of Energy in the Normal Spectrum, Annalen der Physik 4 (1901) 553-563.

[44] R.S.J. Tol, T.K. Berntsen, B.C. O'Neill, J.S. Fuglestvedt, K.P. Shine, Y. Balkanski, L. Makra, Metrics for Aggregating the Climate Effect of Different Emissions: A Unifying Framework, Economic and Social Research Institute, Dublin, Ireland, 2008.

[45] IPCC -Intergovernmental Panel on Climate Change-, Climate Change 1990: The IPCC Scientific Assessment, Contribution of Working Group II to the First Assessment Report of the IPCC, J.T. Houghton, G.J. Jenkins, J.J. Ephraums (Eds.), Cambridge University Press, Cambridge, UK, 1990.

[46] D.A. Lashof, D.R. Ahuja, Relative contributions of greenhouse gas emissions to global warming, Nature 344 (1990) 529-531.

[47] H. Rodhe, A comparison of the contribution of various gases to the greenhouse effect, Science 248 (1990) 1217-1219.

[48] D.G. Victor, Calculating greenhouse budgets, Nature 347 (1990) 431.

[49] N. Rasmussen, WASH-1400 The Reactor Safety Study, WASH 1400, Nuclear Regulatory Commission, USA, 1975.

[50] M. Manning, A. Reisinger, G. Bodeker, Global Warning Potentials and alternative metrics, New Zealand Climate Change Research Institute, School of Government, Victoria University of Wellington, Wellington, NZ, 2009.

[51] IPCC -Intergovernmental Panel on Climate Change-, Climate Change 1995: The Science of Climate Change. Contribution of Working Group I to the Second Assessment Report of the IPCC, J.T. Houghton, L.G. Meira Filho, B.A. Callander, N. Harris, A. Kattenberg, K. Maskell (Eds.), Cambridge University Press, Cambridge, UK, New York, USA, 1996.

[52] M. Kandlikar, The relative role of trace gas emissions in greenhouse abatement policies, Energy Policy 23 (1995) 879-883. 
[53] A.S. Manne, R.G. Richels, An alternative approach to establishing trade-offs among greenhouse gases, Nature 410 (2001) 675-677.

[54] K.P. Shine, J.S. Fuglestvedt, K. Hailemariam, N. Stuber, Alternatives to the global warming potential for comparing climate impacts of emissions of greenhouse gases, Climatic Change 68 (2005) 281-302.

[55] K.P. Shine, T.K. Berntsen, J.S. Fuglestvedt, R. BieltvedtSkeie, N. Stuber, Comparing the climate effect of emissions of short- and long-lived climate agents, Philosophical Transactions of The Royal Society A 365 (2007) 19031914.

[56] C. Gigliarano, K. Mosler, Constructing indices of multivariate polarization, Journal of Economic Inequality 7 (2009) 435-460.

[57] E. Maasoumi, G. Nickelsburg, Multivariate Measures of Well-Being and an Analysis of Inequality in the Michigan Data, Journal of Business and Economic Statistics 6 (1988) 327-334.

[58] IEA -International Energy Agency-, $\mathrm{CO}_{2}$ Emissions from Fuel Combustion (2012 edition), OECD, Paris, 2012

[Available at: http://data.iea.org/ieastore/statslisting.asp]

[59] T.A Boden, G. Marland, R.J. Andres, Global, Regional, and National Fossil Fuel $\mathrm{CO}_{2}$ Emissions. Carbon Dioxide Information Analysis Center (CDIAC), Oak Ridge National Laboratory, U.S. Department of Energy. Oak Ridge, Tenn., U.S.A., 2011

[Available at: http://cdiac.ornl.gov/trends/emis/overview_2008.html].

[60] USEPA -U.S. Environmental Protection Agency-, Global Non-CO2 GHG Emissions: 1990-2030. EPA, Washington DC, USA, 2012b [Available at: http://www.epa.gov/climatechange/EPAactivities/economics/nonco2 projections.html]

[61] EIA -U.S. Energy Information Administration-, International Energy Statistics, U.S. Department of Energy, Washington DC, 2013 [Available at: http://www.eia.doe.gov/ emeu/international/contents.html] 
[62] FAO -Food and Agriculture Organization of the United Nations-, FAOSTAT, Rome, Italy, 2013

[Available at: http://faostat3.fao.org/home/index.html\#DOWNLOAD]

[63] IPCC -Intergovernmental Panel on Climate Change-, Good practice guidance and uncertainty management in national greenhouse gas inventories, 2000 [Available at: www.ipcc-nggip.iges.or.jp/public/gp/english]

[64] IPCC -Intergovernmental Panel on Climate Change-, IPCC guidelines for national greenhouse gas inventories, 2006 [Available at: www.ipccnggip.iges.or.jp/public/2006gl index.html]

[65] A.A. Drăgulescu, V.M. Yakovenko, Evidence for the exponential distribution of income in the USA, The European Physical Journal B 20 (2001b) 585-589.

[66] V. Venkatasubramanian, Fairness is an emergent self-organized property of the free market for labor, Entropy 12 (2010) 1514-1531. 